Slavica

bruxellensia

\section{Slavica bruxellensia}

Revue polyphonique de littérature, culture et histoire

slaves

$11 \mid 2015$

Littérature et philosophie

\title{
Adam Mickiewicz, Prose artistique. Contes, essais, fragments
}

Christine Masson

\section{OpenEdition}

Journals

Édition électronique

URL : http://journals.openedition.org/slavica/1679

DOI : 10.4000/slavica.1679

ISSN : 2034-6395

Éditeur

Université libre de Bruxelles - ULB

Référence électronique

Christine Masson, «Adam Mickiewicz, Prose artistique. Contes, essais, fragments », Slavica bruxellensia [En ligne], 11 | 2015, mis en ligne le 21 janvier 2015, consulté le 22 septembre 2020. URL : http:// journals.openedition.org/slavica/1679; DOI : https://doi.org/10.4000/slavica.1679

Ce document a été généré automatiquement le 22 septembre 2020.

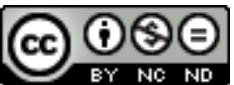

Les contenus de Slavica bruxellensia sont mis à disposition selon les termes de la Licence Creative Commons Attribution - Pas d'Utilisation Commerciale - Pas de Modification 3.0 France. 


\title{
Adam Mickiewicz, Prose artistique. Contes, essais, fragments
}

\author{
Christine Masson
}

\section{RÉFÉRENCE}

Adam Mickiewicz, Prose artistique. Contes, essais, fragments, introduction et rédaction par Joanna Pietrzak-Thébault, Wydawnictwo Instytutu Badań Literackich PAN, Varsovie, 2013, $512 \mathrm{p}$. 
Quel amoureux de la culture polonaise pourrait ne pas connaître le nom de Mickiewicz? Figure phare du romantisme et guide spirituel de la nation en ses temps les plus troublés, il a laissé une empreinte indélébile dans l'histoire de son pays. Depuis le $\mathrm{XIX}^{\mathrm{e}}$ siècle, ses œuvres ont passionné une myriade de lecteurs et fait l'objet d'un nombre invraisemblable études. Il serait donc légitime de s'interroger sur la nécessité d'un nouvel ouvrage consacré à ce grand auteur. Pourtant, c'est bien un vent de fraîcheur qu'apporte Prose artistique. Contes, essais, fragments composé par Joanna PietrzakThébault qui propose, selon une démarche scientifique très rigoureuse, une compilation des textes originaux rédigés en français, ainsi que leurs commentaires, dans une édition bilingue.

2 La connaissance $d u$ français de Mickiewicz n'est un secret pour personne et elle a d'ailleurs été louée de son vivant. Certains de ses écrits en langue française sont même devenus de véritables sujets d'étude, comme ses cours du Collège de France ou de l'Académie de Lausanne, ses articles de presse ou sa correspondance. Pourtant, outre cet héritage fameux, il en est un autre, fragmentaire et méconnu, que le présent ouvrage ambitionne de faire connaître. Il s'agit de faire resurgir toute cette littérature, morcelée au fil des éditions et figée dans sa traduction polonaise, dans sa langue originale selon une logique d'édition cohérente et chronologique, mais, surtout, s'appuyant sur le bilinguisme. La structure est la suivante : chaque texte est suivi de notes informatives mettant en lumière d'abord les références textuelles, ensuite les conditions d'édition et enfin les variantes. Ce procédé est très astucieux, car il oriente un éventuel lecteur néophyte, exclusivement intéressé par le contenu du texte, mais fournit également au spécialiste des outils d'analyse très précis.

3 L'amplitude des textes réunis est assez large. Adam Mickiewicz s'est essayé sur des thèmes qui lui tenaient à cœur comme le théâtre polonais, la fonction du poète, l'importance des bibliothèques ou encore la littérature russe ; il a entrepris de raconter l'histoire de Saint Adalbert et de l'Italie. En marge de ces sujets plutôt généraux, il a aussi livré des considérations métaphysiques et un court récit en prose sur les campagnes napoléoniennes. En comparaison avec ses chefs-d'œuvre les plus connus, ses écrits en français sont plus atypiques, voire personnels, et permettent de découvrir une autre facette de l'écrivain.

4 En conclusion, Prose artistique. Contes, essais, fragments d'Adam Mickiewicz est un ouvrage à mettre entre toutes les mains, des novices aux plus expertes. Il offre non seulement de beaux textes littéraires et réflexions, mais permet également de découvrir un nouvel aspect de l'œuvre d'Adam Mickiewicz, souvent occulté. Et cela, sans oublier l'incroyable opportunité d'avoir sous les yeux un précieux livre bilingue ! 
INDEX

Index géographique : Pologne

Index chronologique : romantisme, XIXe siècle

Mots-clés : émigration polonaise, littérature polonaise, romantisme polonais

\section{AUTEURS}

\section{CHRISTINE MASSON}

Étudiante de Master européen ULB/Université de Varsovie 